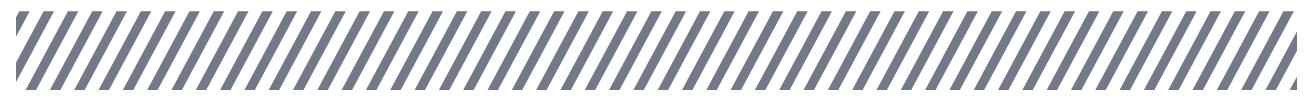

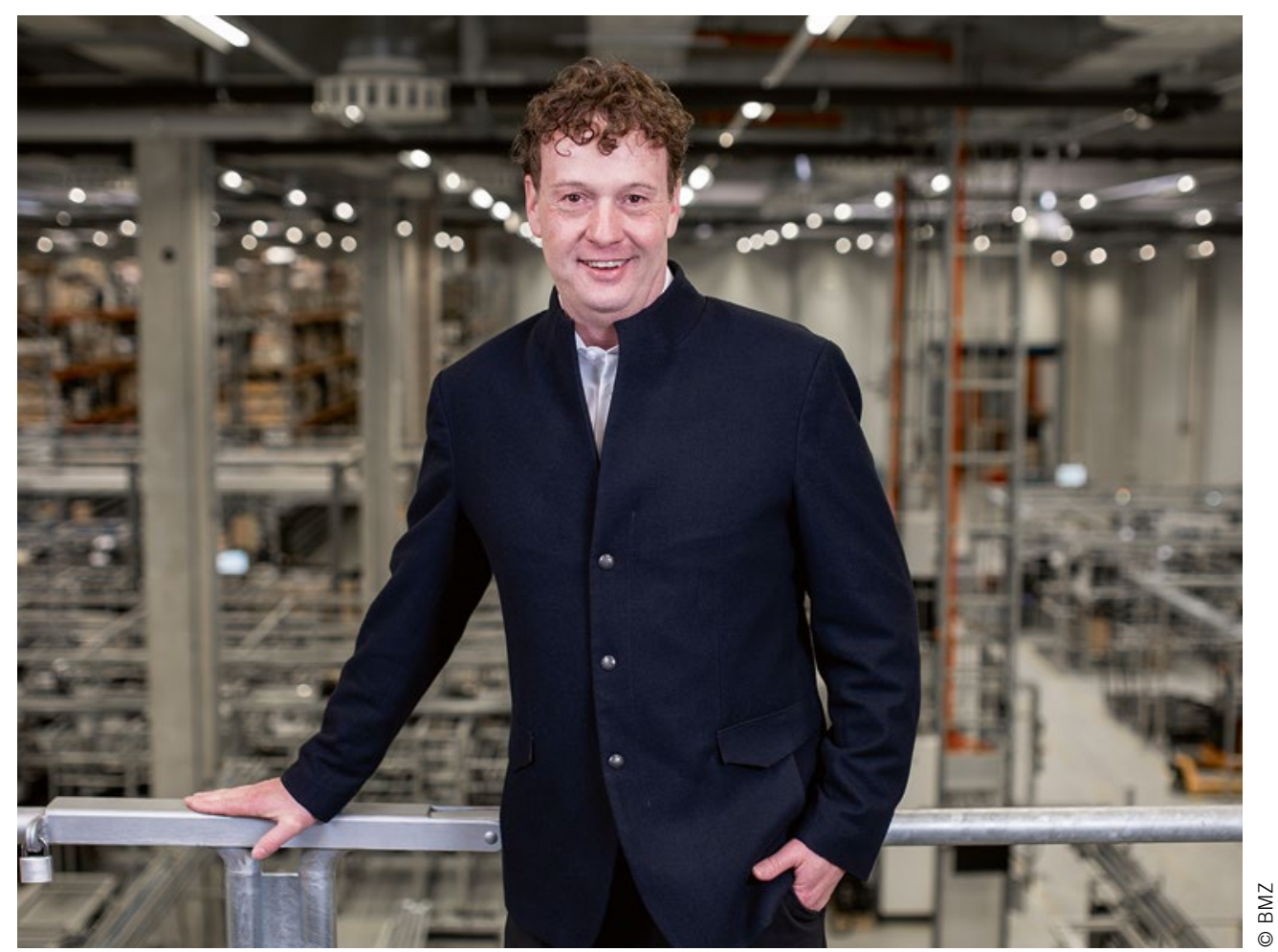

Sven Bauer

CEO \& Founder, BMZ Group

\section{Zeitalter der Elektromobilität}

Die Herausforderung des Klimawandels werden wir nur meistern, wenn in absehbarer Zeit der Verbrauch fossiler Brennstoffe rapide abnimmt. Eine echte Energiewende ist möglich. Wir können alle Bereiche - Strom, Verkehr und Wärme dekarbonisieren. Dafür benötigen wir Unmengen von Energiespeichern. Branchenanalysten sind sich einig, dass sich der weltweite Bedarf an Energiespeichern von derzeit 120 Gigawattstunden bis 2025 verdreifachen wird.

Jeder fünfte Job in Deutschland hängt bald an der Batterie. Den kabellosen Rasenmäher, die kabellose Bohrmaschine, den Laptop-Akku - all das gab es auch vor zehn Jahren schon. Jetzt bricht das Zeitalter der Elektromobilität an. Wir müssen uns auf die Chance konzentrieren, die elektrisch betriebene Fahrzeuge für uns im Alltag bedeuten können. Der durchschnittliche Arbeitnehmer legt täglich eine Strecke von knapp $40 \mathrm{~km}$ zurück - eine Reichweite, die jedes Elektrofahrzeug heutzutage ohne Probleme schafft. Entwicklungsseitig werden Kapazitäten für 400 bis $500 \mathrm{~km}$ in Aussicht gestellt. Und auch das Stromnetz können wir mit Energiespeichern entlasten. Sogenannte Energy-Storage-Systeme finden sowohl im privaten als auch im gewerblichen Umfeld Einsatz und speichern die erzeugte Energie einer PV-Anlage.

In Zukunft werden die Energiespeicher miteinander vernetzt, verfügbare Kapazitäten somit analog zum Cloud-Modell geteilt.
Und kommen wir an den Punkt, an dem die Fahrzeugbatterie „ausgedient“ hat, geben wir ihr ein zweites Leben. Zum PeakShaving sind $80 \%$ Restkapazität, mit der eine Batterie nicht unbedingt mehr in der reichweitengesteuerten Elektromobilität, aber im Energiespeicher-Bereich noch brauchbar ist, absolut ausreichend. Die modulare Bauweise der Systeme, wie BMZ sie marktführend umsetzt, ermöglicht einen aufwandsgeringen Umbau der Batterien. Das Modul kann systemübergreifend weiterverwendet werden, lediglich das Batterie-Management-System benötigt eine neue anwendungsspezifische Konfiguration. Abgesehen vom Recycling, das ganz am Ende der Lebensdauer einer Batterie steht und die Rohstoff-Ressourcen schont, nimmt der Anteil endlicher Materialien in einer Zelle von Produktgeneration zu Produktgeneration ab. Waren früher $30 \%$ Kobalt in einer Batteriezelle enthalten, sind es heute nur noch $2 \%$. Ziel ist es, eine „grüne Zelle“ zu entwickeln - aber davon sind wir noch etwas entfernt. Immerhin steckt in der Lithium-IonenTechnologie noch Entwicklungs- und Optimierungspotenzial für die nächsten zehn Jahre.

Liebe Leserinnen und Leser, Sie sehen, es gibt zahlreiche Ansätze und Lösungen über den gesamten Lebenszyklus einer Batterie hinaus. Wir müssen die Potenziale nur erkennen, Chancen nutzen und neue Wege ausprobieren. Für eine nachhaltig saubere und mobile Zukunft. 